\title{
Desarrollo, populismo y neoliberalismo. Pensar Latinoamérica
}

\author{
Rafael Böcker Zavaro \\ rafael.bocker@urv.cat \\ Universitat Rovira i Virgili
}

Resumen: Este artículo parte del concepto de populismo en cuanto categoría vinculada a estrategias ideológicas y modelos de desarrollo en América Latina. Luego se ofrece un análisis sintético sobre la orientación politico-ideológica de la agenda de los gobiernos latinoamericanos durante las últimas décadas: se intentará comprobar su vinculación con las politicas expansivas y desarrollistas, o bien con aquellas politicas de ajuste de tipo neoliberal. Se parte de la premisa de que el modelo de desarrollo planteado está conectado a una decisión política determinada en función de diferentes perspectivas ideológicas. Finalmente, se mencionan algunos ejemplos de países sudamericanos, en particular el de Argentina durante las presidencias de Néstor y Cristina Kirchner.

Palabras claves: populismo, desarrollo, neoliberalismo, Estado, América Latina.

Abstract: This article examines the concept of populism as a category linked to ideological strategies and development models in Latin America. It then offers a synthetic analysis of the political and ideological orientation of Latin American governments' agendas during recent decades. It attempts to verify their relationship with either expansive and developmentalist policies or with neo-liberal adjustment policies. It is based on the premise that the proposed development model is connected to specific political decisions, each based on different ideological perspectives. Finally, the study mentions some examples from South American countries, particularly the case of Argentina during the presidencies of Néstor and Cristina Kirchner.

Keywords: populism, development, neoliberalism, state, Latin America 


\section{Introducción}

Han pasado veinte años desde que muchos países de América Latina marcaran un cambio de época a partir de las luchas de los movimientos sociales y organizaciones indígenas contra los ajustes neoliberales y la posterior emergencia de gobiernos posneoliberales, caracterizados de modo genérico como progresistas (Svampa, 2015). Desde inicios del siglo xxi se fue conformando un grupo amplio de países donde llegaron al poder gobiernos progresistas (Chile con Lagos y Bachelet; Brasil con Lula da Silva y Dilma Rousseff; Uruguay bajo el Frente Amplio; Argentina con los Kirchner; Ecuador con Rafael Correa; Bolivia con Evo Morales; la Venezuela bolivariana; México con López Obrador, entre otros).

Entre estos gobiernos progresistas posneoliberales, se suele destacar en la literatura como experiencias populistas a Hugo Chávez, Evo Morales, Rafael Correa, y Néstor y Cristina Kirchner en Argentina. Es decir, no es exactamente lo mismo hablar de nueva izquierda latinoamericana que de populismos del siglo XXI.

Para comenzar, es importante señalar que el populismo es un fenómeno polémico que genera mucha controversia en América Latina y en el mundo. De hecho, a partir del surgimiento de populismos xenófobos y conservadores en los Estados Unidos y Europa, podemos cuestionar frontalmente una idea muy repetida en los medios de comunicación masivos: que en los países menos desarrollados los sistemas de partidos poco institucionalizados facilitan la aparición de outsiders potencialmente populistas, mientras que, en las democracias más avanzadas, el sistema de partidos institucionalizado, estable y dinámico, obstaculiza la irrupción de liderazgos populistas.

La literatura sobre el populismo destaca que en la mayoría de los países de América Latina la integración política fue obra de partidos populistas multiclasistas amplios y programáticamente difusos, mientras que los sistemas de partidos europeos se han estructurado en torno a variables de clase y están dotados de una continuidad y organización ideológica.

Ahora bien, ello ha cambiado y es un aspecto central, debido a que han aparecido partidos populistas entre los países desarrollados cuyo surgimiento se vio favorecido por la crisis del 2008.

Si bien el populismo ha sido un objeto central en el estudio de la política latinoamericana desde mediados del siglo $\mathrm{xx}$, se trata de un término vago e impreciso que abarca una multitud heterogénea de fenómenos: ha sido empleado para referirse a líderes políticos, partidos, ideologías, movimientos o periodos históricos. También a movilizaciones de masas (de raíces urbanas o rurales), actitudes discursivas, regímenes y formas de gobierno, mecanismos de democracia directa 
(referéndums, participación), dictaduras, políticas y programas de gobierno, reformismos, etc. (Mackinnon y Petrone, 1998).

Todos creemos saber qué es, pero, cuando se nos pide que expliquemos su significado, no sabemos muy bien cómo continuar. Aquellos que usan el término populismo saben intuitivamente lo que significa, pero parece haber cierta dificultad para construir el concepto y explicar su contenido (Mackinnon y Petrone, 1998).

Como se verá, el problema no radica en el abordaje empírico y la medición de grados de populismo, sino en su conceptualización, producto de la amalgama de situaciones históricas en que se ha presentado, por ejemplo, desde la Argentina de Juan Domingo Perón (populismo clásico), pasando por el Perú de Juan Velasco Alvarado (populismo revolucionario militar), los denominados neopopulismos neoliberales de la década de 1990 en Argentina y Perú principalmente, y los populismos propios del siglo XXI.

Por ello, el término populismo se ha transformado para algunos en una "etiqueta política que designa una amplia gama de fenómenos, partidos, movimientos, líderes democráticos y autoritarios de distintas épocas, lugares y afiliaciones ideológicas" (Ruiz, 2006: 103).

La dificultad para construir el concepto de populismo en la actualidad reside, además, en el hecho de que se refiere a fenómenos muy diferentes, por ejemplo, según se trate de Europa o América Latina. La idea de populismo que más se conoce hoy en Europa es la experiencia populista nacionalista, que es la mayoritaria y la que más preocupación genera en la opinión pública, en el sistema político tradicional y en las instituciones en general. Se trata de un populismo con un discurso xenófobo, antieuropeísta y conservador. Claramente se trata de una ideología de derecha. No obstante, también existen políticos y partidos políticos de izquierda a los que se les han atribuido características populistas no solo en Europa central y del este, sino también en España (Podemos) o Francia (La Francia Insumisa de Mélenchon).

Por su parte, la idea de populismo que más se conoce en América Latina es la experiencia populista reformista, en general progresista, que ha sido la mayoritaria y la que más preocupación ha generado en los medios de comunicación, en los grupos de poder y en los sectores conservadores. Sin embargo, también ha surgido recientemente la derecha populista en América Latina con la llegada al poder de Bolsonaro, que posee una ideología y un discurso similar al de los populismos nacionalistas europeos y al de Donald Trump. 


\section{Populismo y desarrollo}

En los medios de comunicación hegemónicos el populismo aparece como la negación de los valores elementales de la democracia representativa al poner el énfasis en la cuestión del liderazgo "demagógico" y la "manipulación de las masas". Por ello, el término tiene una fuerte carga negativa que es más bien rechazada por aquellos que la reciben.

Existe cierto consenso en la literatura sobre populismo respecto al hecho de que la falta de pesos y contrapesos entre los poderes del Estado, así como la existencia de democracias fuertemente presidencialistas, contribuye a la acumulación excesiva de poder en el ejecutivo. El poder ejecutivo concentrado en torno al presidente acumula poder gracias a que la "ampliación" de poderes presidenciales se incluye en las disposiciones constitucionales. Asimismo, en algunos casos los presidentes contrarrestan la oposición o la falta de apoyo del legislativo gracias a estos poderes, que les permiten legislar por decreto "saltándose" al parlamento. Aquí el gobernante respondería únicamente ante el electorado, que decidiría de manera plebiscitaria en las elecciones, lo que contribuiría a crear las condiciones para la emergencia de liderazgos políticos de corte populista.

Así, desde este punto de vista, podría emerger el populismo, facilitado por diseños institucionales fuertemente presidencialistas, la concentración de poder en manos de un ejecutivo fuerte y la persistencia de culturas políticas autoritarias y delegativas.

En contraposición, también se aborda el fenómeno populista en América Latina a partir de estudios que ofrecen explicaciones favorables de ciertas experiencias populistas. Tal es el caso de Ernesto Laclau, que concebía el populismo como una "estrategia discursiva" de construcción de una frontera política que divide a la sociedad en dos campos enfrentados y convoca "a los de abajo" contra "los que tienen el poder", al pueblo contra la oligarquía. De este modo, desde el enfoque ideológico, Ernesto Laclau plantea un modo de construcción de lo político distante del paradigma sociológico, con el retorno de la noción del pueblo como categoría política contingente y la dicotomización del espacio social como precondición para la ruptura populista, dada la convergencia entre demandas insatisfechas e irrupción de un líder (Laclau, 2005; 2006). En su visión, el populismo existe siempre cuando las identidades colectivas se construyen en torno a la dicotomía entre los de abajo y los de arriba (Laclau, 1987). Para Laclau, es populista la reconstrucción politizada de identidades desarticuladas a través de un discurso que divide el espacio social en dos campos políticos dicotómicos, lo que permite constituir al pueblo (los de abajo) en una nueva identidad popular opuesta a las oligarquías dominantes (Laclau, 1987). 
En 2005, Laclau dio a conocer su libro-síntesis La razón populista, donde desarrollaba la premisa de que el populismo constituye una lógica inherente a lo político y que, como tal, este se erigiría en una plataforma privilegiada para observar el espacio político. Lejos de la condena ética impulsada por la visión heterónoma, Laclau proponía visualizar el populismo como ruptura a partir de la dicotomización del espacio político (dos bloques opuestos) y de una articulación de las demandas populares por la vía de la lógica de la equivalencia.

En el populismo clásico las distinciones amigo-enemigo y oligarquía-pueblo respondían a un principio central. Esta construcción antagónica no va acompañada de una definición ideológica clara, sino que se caracteriza por la ambigüedad y un discurso ecléctico, siendo ilustrativo de ello el peronismo. La ambigüedad e imprecisión del discurso populista se explica por su función. Los símbolos populistas deben representar a este pueblo heterogéneo, no deben confundir ni agredir la identidad separada de cada uno de ellos, por lo cual el discurso y los símbolos utilizados deben ser imprecisos y ambiguos (Laclau, 1987). Bajo esa lógica, cuanto más extenso es el conjunto popular al cual se dirige el discurso populista, más ambiguo e impreciso tienen que ser los símbolos empleados. Por esto, explica Laclau, los símbolos populistas son utilizados por las más variadas corrientes ideológicas y políticas. De aquí se desprende la dificultad para conceptualizar y delimitar un fenómeno político que adopta distintas formas y representaciones de acuerdo a la realidad social y política en la que se desarrolla. En virtud de lo anterior, una perspectiva comparativa chocaría irremediablemente con este carácter camaleónico del populismo.

El populismo es una estrategia discursiva, por ello no tiene sentido definirlo como un régimen político o hablar de un gobierno populista (Laclau y Mouffe, 1987; Laclau, 2005). Desde esta perspectiva, el populismo no configura tampoco una ideología determinada (puede ser de derecha, por ejemplo, contra los extranjeros, o de izquierda, contra la oligarquía); es simplemente una forma de acumular poder, un modo de construcción política. La gran diferencia entre populismo de izquierda y populismo de derecha es cómo se construye ese pueblo; porque ese pueblo no es la población, el pueblo es una construcción política (Mouffe, 2018).

Así, el nuevo tipo de populismo en América Latina, denominado populismo de derecha, ha surgido con la llegada al poder de Bolsonaro en Brasil. No solo es un promotor de políticas neoliberales (como las derechas conservadora y liberal), sino que además se presenta con un discurso populista xenófobo, antiinmigración y de mano dura, siguiendo el ejemplo de Donald Trump y de la derecha populista europea. De este modo, Bolsonaro tiene un discurso populista conservador y autoritario, dirigido a polarizar la sociedad, confrontándose directamen- 
te con el modelo de país promovido anteriormente por los gobiernos progresistas de Lula da Silva y Dilma Rousseff, también en términos de política de pública.

De esta manera, existen muchas demandas heterogéneas que tienen que articularse en el momento de hegemonía del populismo, sea de izquierda o de derecha, y cada uno de ellos intenta hacerlas converger a partir de un principio articulatorio (Laclau, 2005), que en el pasado muchas veces ha sido un líder carismático, pero que puede ser cualquier elemento emocional. Porque cuando se habla de crear un pueblo en realidad se está hablando de la construcción de un nosotros, gente que se reconoce y se identifica como una colectividad.

Desde este punto de vista, mediante la articulación de una "cadena de equivalencias" que eslabona diferentes demandas insatisfechas, el populismo de izquierda es un camino viable para desmontar la formación hegemónica neoliberal, ampliar la democracia y frenar al populismo derecha (Mouffe, 2018). Esta sería la gran diferencia respecto a la izquierda radical que existía antes, la cual no se postulaba como un partido de poder sino de denuncia. En cuanto a los partidos socialdemócratas, o socioliberales, estos movimientos no buscan llegar al poder para transformar o poner en tela de juicio la hegemonía neoliberal.

Así, la experiencia populista latinoamericana más difundida ha contemplado, como principio articulatorio, dichas demandas heterogéneas en el Estado social. De hecho, Sachs (1990) y Dornbusch y Edwards (1991), desde una perspectiva económica, reducen el populismo a políticas expansivas y redistributivas, pues lo limitan a las experiencias reformistas de las décadas de 1930, 1940 y 1950. De hecho, la definición clásica de populismo en América Latina ha sido la de un Estado interventor $y$ asistencialista que controla los servicios públicos, es dueño de empresas y alienta el proceso de industrialización a través de regulaciones, subsidios y protección aduanera.

Así, Dornbusch y Edwards (1989) analizan la macroeconomía del populismo como una reacción a las experiencias monetaristas. Por populismo, estos autores entienden una aproximación económica que enfatiza la redistribución y resta importancia a los riesgos de la inflación y el déficit financiero, los constreñimientos externos y la reacción de los agentes económicos ante agresivas políticas contrarias al mercado. En una fase inicial existe insatisfacción con el crecimiento económico alcanzado por los países, sumado a una enorme desigualdad que proporciona la base para programas económicos y políticas radicales asociados a una fuerte expansión del gasto. En una fase posterior, los policy makers rechazan explícitamente el paradigma conservador, y los peligros asociados al déficit fiscal son calificados de exagerados y desacreditados. 
En ese sentido, los gobiernos de la derecha liberal (Piñera en Chile y Macri en Argentina, entre otros) y de la derecha populista (Bolsonaro en Brasil) que siguen políticas económicas neoliberales afirman con frecuencia que no están dispuestos a volver a políticas "populistas". Igualmente, los partidos políticos en la oposición de ideología conservadora y/o neoliberal han planteado la necesidad de un cambio frente a este tipo de políticas "clientelistas". De hecho, se ha producido un vuelco a la derecha en muchos países de América Latina (Oliver, 2016), poniendo fin al ciclo de gobiernos progresistas como un bloque regional.

Como ya hemos comentado, la etiqueta de "populista" ha tenido una fuerte carga negativa por ser vista como sinónimo de clientelista, autoritario y corrupto (Mackinnon y Petrone, 1998). Pero a diferencia de épocas en las cuales la visión descalificadora era la dominante (como durante el populismo clásico), el actual retorno del populismo se inserta en escenarios políticos e intelectuales más complejos y disputados. Este tipo de críticas en general han puesto como ejemplo a la Venezuela de Nicolás Maduro, donde algunos principios de la democracia liberal se han visto limitados: Estado de derecho, división de poderes y libertades individuales.

Asimismo, la oposición a los gobiernos populares utilizó de manera desvirtuada y negativa el término populismo para referirse a procesos muy diversos que, si bien presentaban puntos en común, con esta palabra eliminaron toda diferencia posible. Al llamarlos a todos populismos, se borró la diversidad, que era muy rica. Ello derivó en una batalla por el sentido, donde se trabajó para eliminar el legado simbólico de estos gobiernos populares enmarcados en experiencias progresistas posneoliberales.

Por ello, y teniendo en cuenta también las diferencias entre sí, las características políticas que adoptaron los gobiernos de Hugo Chávez en Venezuela (19992013), Néstor y Cristina Fernández de Kirchner en Argentina (2003-2007 y 2007-2015, respectivamente), Rafael Correa en Ecuador (2007-2017) y Evo Morales en Bolivia (2006-2019), todos ellos países con una notoria y persistente tradición populista, propiciaron el retorno de un uso del concepto de populismo, en sentido fuerte, a partir de la reivindicación del Estado - como constructor de la nación luego del pasaje del neoliberalismo-, del ejercicio de la política como permanente contradicción entre dos polos antagónicos - el nuevo bloque popular versus sectores de la oligarquía regional o medios de comunicación dominantes- (Laclau), y, por último, de la centralidad de la figura del líder.

De esta manera, la irrupción de Chávez, Correa, Morales y los Kirchner aportaron una serie de elementos a analizar cuyas raíces muestran una enorme similitud con el populismo clásico: el carácter redistributivo, la concentración del 
poder estatal, la regulación de la economía, el desplazamiento del mercado como principal asignador de recursos y, por último, la vuelta hacia un Estado interventor (proceso vinculado con la nacionalización de los recursos naturales, la estatización de empresas estratégicas y el reparto de tierras).

Por el contrario, y a modo de ejemplo, el programa de gobierno de Bolsonaro y su primer año en la presidencia indican que implementará un conjunto de políticas de ajuste neoliberal similar a las de los gobiernos de la derecha liberal también en el poder en Sudamérica:

- Se trata de achicar drásticamente al Estado reduciendo su prestación de servicios públicos —en especial educación, salud y jubilaciones, áreas de rentabilidad potencial para el sector privado-.

- Propone la privatización de empresas estatales y la reducción de costos para el sector privado.

- En su agenda también plantea la flexibilización laboral y el recorte de derechos de los trabajadores (aguinaldo y vacaciones), además de contener los aumentos salariales e impulsar una reforma tributaria y una reforma previsional.

En suma, este tipo de reformas de ajuste neoliberal recuerdan aquellas implantadas en los países latinoamericanos durante los años noventa y en Europa tras la crisis de 2008, producto de políticas favorables al mercado en el marco de crisis de deudas soberanas. No obstante, preguntarnos si los Estados deben intervenir o no en la economía es erróneo, ya que los mercados no existen por sí solos, sino en un contexto de reglas, leyes, regulaciones y políticas públicas. Por ello, el neoliberalismo no defiende un Estado ausente, sino uno que intervenga activamente para desregular, flexibilizar el mercado laboral, privatizar y subsidiar a los sectores concentrados (Böcker, 2014).

\section{Neoliberalismo y neodesarrollismo}

La hegemonía de la economía neoclásica comenzó en las últimas décadas del siglo xx y obedeció en gran medida al descrédito del análisis keynesiano, a la crisis del estructuralismo latinoamericano y a la decadencia de las perspectivas críticas - neomarxistas - del desarrollo, en las que el subdesarrollo era una consecuencia del proceso continuo de extracción del excedente generado en la periferia por los monopolios industriales del centro (Bustelo, 1998). Este descrédito explica la influencia del pensamiento neoclásico en las ideas y los programas de los principales organismos internacionales, cuyas críticas al intervencionismo gubernamental y el culto a las virtudes del libre mercado procuraron una redefinición del 
Estado en todos sus frentes. Ello quedó reflejado en la década de los ochenta en las denominadas políticas de estabilización, seguidas de una política de ajuste estructural, y en la década de los noventa en el llamado Consenso de Washington. Este pretendía dar respuesta a la crisis de la deuda externa que afloró a partir del año 1982, cuando México anunció la imposibilidad de cumplir con los pagos de su primer paquete de medidas de ajuste estructural para salir de la crisis. Desde esta perspectiva, se trataba de una crisis provocada por el excesivo crecimiento del Estado, por la ineficiencia de las empresas públicas y por la excesiva regulación, proteccionismo y populismo económico, que imposibilitaban el control del déficit público.

En un contexto latinoamericano caracterizado por una agenda neoliberal, se aplicaron un conjunto de medidas que se convertirían en el modelo prototípico del Consenso de Washington y defendían el desarrollo gradual, continuo y armónico y el libre juego de las fuerzas de oferta y demanda (la lógica perfecta del mercado) (Williamson, 1990). Estas medidas consistían, en una primera etapa de estabilización de la economía, en eliminar la inflación y el déficit exterior en cuanto principales desequilibrios macroeconómicos, $y$, en una segunda etapa de ajuste estructural, en generar un modelo de desarrollo orientado al mercado. Además, el Consenso de Washington contemplaba la austeridad y limitación del gasto público para evitar la inflación, las reducciones fiscales de las rentas altas para aumentar las inversiones, los tipos de cambio débiles para favorecer la competitividad, la libertad de los intercambios comerciales, las privatizaciones de las empresas nacionales y del patrimonio de los Estados, la supresión de subvenciones principalmente agrícolas y, sobre todo, la desregulación mediante la eliminación de reglamentaciones y controles que fueran contrarios a la iniciativa económica. Por todo ello, es relevante subrayar las similitudes de estas políticas con las impulsadas por los gobiernos neoliberales latinoamericanos en la actualidad.

Este Consenso, con la participación de los bancos comerciales internacionales y de los gobiernos de los países más ricos bajo el liderazgo de los Estados Unidos, supuso el desmantelamiento de las barreras a la libertad de comercio y a los flujos de capital, y expuso las economías nacionales a la disciplina de los mercados. El relato legitimador era que, mediante la aplicación de la libertad de comercio al desarrollo, se reduciría la pobreza al aumentar los índices de crecimiento e introducir el capitalismo moderno en las regiones más pobres del planeta. El culto a la competencia aduce como legitimación la creencia de que el libre comercio acaba conduciendo a los países a un óptimo crecimiento y bienestar. Sin embargo, este culto y estos supuestos trajeron "algo muy diferente", o lo que Fitoussi y Rosanvallon (1996) han denominado "la nueva era de las desigualdades", que afectó claramente al Sur. 
Así, una parte importante del pensamiento heterodoxo en América Latina experimentó una severa transformación a partir de la década de los ochenta. La visión crítica del viejo estructuralismo desarrollista tendió a perder peso. Se trataba de una perspectiva que destacaba el carácter subordinado del crecimiento económico en la periferia y la necesidad de formular un pensamiento económico autónomo acorde a la problemática específica de la región. Comenzó a imponerse una visión sumamente despolitizada de las transformaciones económicas, $y$, en consonancia con los postulados más profundos de la teoría liberal, el desarrollo pasó a ser un problema del agente individual, en un contexto donde este tiene las herramientas para aprovechar las ventajas del progreso tecnológico (Pinazo y Piqué, 2011). De este modo, fueron perdiendo peso categorías como centro y periferia, así como el análisis de los condicionantes vinculados a los intereses de las distintas fracciones de clase involucradas $y / o$ a las estructuras de propiedad, frente a una realidad pensada en términos de "agentes" potencialmente homologables y competitivos (Nahon et al., 2006; Casparrino, 2008).

A partir de este nuevo contexto, con los años fue formándose un nuevo consenso teórico que, bajo el nombre de neoestructuralismo o neodesarrollismo,"nació como una crítica al recetario neoliberal y como una superación del viejo desarrollismo" (Pinazo y Piqué, 2011: 9). Según Romo (2007), el neoestructuralismo se construye más sobre una crítica de las consecuencias sociales del ajuste que sobre una crítica radical de sus fundamentos teóricos esencialmente neoclásicos y neoliberales.

Según Bresser-Pereira (2007), las diferencias entre el desarrollismo de la década de 1950 y el nuevo desarrollismo se explican, en primer lugar, por los cambios ocurridos en el contexto capitalista mundial, que pasó de los "años dorados" a la actual fase de globalización. Para Gereffi (2001), existe una aguda división entre los teóricos que consideran la globalización como una restricción de las perspectivas de desarrollo de las naciones periféricas y los que ven los vínculos que implica la globalización, la cual no solo representa restricciones, sino también oportunidades para el avance de los países en desarrollo.

En el caso de las políticas neodesarrollistas, la crisis no resuelta a inicios del siglo xxi ha provocado la recuperación del "modelo de crecimiento hacia adentro" en unos casos, y en otros del "modelo de crecimiento hacia afuera" (Sunkel, 1991).

De esta manera, conforme el capitalismo fue ingresando en su era neoliberal, se fue conformando en los países latinoamericanos una nueva izquierda que se planteó el desafío de la ruptura con el modelo neoliberal y la construcción de alternativas superadoras de ese modelo, que se han designado como posneoliberales, progresistas o populares. 
Algunos de estos gobiernos progresistas han sido más izquierdistas, como el de Evo Morales, Hugo Chávez y Rafael Correa, y otros han sido de centroizquierda, como en Argentina, Brasil, Uruguay, Chile y, más recientemente, México con López Obrador. Las diferencias existentes entre ambos grupos de gobiernos progresistas residen, por ejemplo, en el tipo de democracia que cada uno de ellos ha tenido: en los gobiernos más izquierdistas se ha abierto un proceso constituyente para crear una nueva Constitución y una nueva Asamblea Constitucional que cuestionan el tipo de democracia liberal, mientras que en los gobiernos de centroizquierda no se ha hecho (Svampa, 2015).

Pero todos estos gobiernos progresistas han tenido en común implementar políticas populares y posneoliberales. La denominación progresista, de significación bastante amplia, remite a la Revolución francesa y hace referencia a las corrientes ideológicas que abogaban por las libertades individuales y el cambio social. Así, la denominación genérica de progresismo abarcaría corrientes ideológicas y perspectivas políticas diversas, pero que tienen dos cosas en común:

1) se trata de gobiernos posneoliberales o antineoliberales, con un rol más activo del Estado en lo social y económico, y

2) comparten un esfuerzo común en la integración latinoamericana, a partir de la creación de la UNASUR y del enfrentamiento contra la injerencia norteamericana mediante tratados de libre comercio como el ALCA.

Estos gobiernos surgieron como respuesta a procesos de crisis generados por el neoliberalismo y se convirtieron en gobiernos de reconstrucción. Sin embargo, si bien estos procesos fueron en general bastante exitosos en la recomposición de los tejidos sociales, económicos y políticos, no consiguieron la consolidación de dichos esfuerzos y no lograron la irrevocabilidad de las conquistas, lo que derivó en cambios de rumbos políticos hacia gobiernos neoliberales. De este modo, es urgente llevar a cabo un examen autocrítico para revisar las dificultades y los puntos débiles de las experiencias progresistas, ya que muchos de estos procesos continúan siendo alternativas electorales en los países donde se llevaron a cabo.

No obstante, la experiencia histórica indica que las crisis generadas por el neoliberalismo no pueden tener soluciones neoliberales debido a la incapacidad de las teorías ortodoxas para abordar las causas de la crisis y de las políticas de austeridad para salir de ella.

A raíz de los cambios en los últimos años en muchos países sudamericanos hacia gobiernos con una impronta neoliberal, comenzó a manifestarse más claramente que las políticas de austeridad están dirigidas a los recursos y capacidades del Estado y a los salarios de los trabajadores. Con ello se sustraen de la economía real enormes recursos que minan el bienestar de la población y la demanda agre- 
gada en cuanto palanca de crecimiento económico y generación de empleo. De este modo, los países podrían entrar en números rojos al tener que hacer frente a los condicionamientos de ajuste de los organismos internacionales de crédito y a crecientes tasas de interés para contraer nueva deuda (Böcker, 2014).

Los organismos de crédito internacionales son responsables de crear recetas, paquetes de medidas cerrados que desconocen los contextos internacionales. Porque no es lo mismo impulsar políticas neoliberales en la década de 1990, cuando el mundo estaba involucrado de lleno en el libre mercado, que en la actualidad. Por ejemplo, el presidente argentino Mauricio Macri implantó un neoliberalismo desregulado y abierto al exterior en un mundo que se había vuelto cada vez más proteccionista. Así, la "lluvia de inversiones" que se prometió nunca llegó simplemente porque el mundo ya no traslada sus inversiones a los países periféricos, sino que las potencias trabajan para que los grandes inversores se queden en los países centrales.

Contrariamente, las políticas neoliberales de dolarización, endeudamiento y ajuste son las que llevaron el país a la crisis actual. En Argentina, el ajuste recesivo que provocó el gobierno con la devaluación, la quita de retenciones, el aumento de tarifas y los despidos no es un efecto no deseado de la política económica, es el punto de partida de un programa orientado a modificar estructuralmente la distribución del ingreso. Mientras más tarden en asumirlo los sectores afectados, que son las mayorías populares, más a fondo avanzará el macrismo en la configuración de un nuevo escenario social.

\section{Extractivismo y primarización}

En los últimos años, varios autores coinciden en que lo que ha ido sucediendo en Sudamérica es una profundización del modelo extractivista y primario exportador desde finales de la década de los setenta, si bien con algunas características distintivas (Böcker y Manzoni, 2015).

Y no solo se ha desarrollado este modelo extractivista durante las etapas marcadas por los gobiernos neoliberales, sino también por gobiernos progresistas. Quizás la crítica más repetida desde la heterodoxia ha sido que el neodesarrollismo intenta articular en el mismo proceso de desarrollo la industrialización y el neoextractivismo (Féliz, 2008, 2012). Así, Svampa (2015) plantea que, lejos ya de las caracterizaciones que a inicios del siglo xxi aludían a un "giro a la izquierda", la reflexión sobre los gobiernos progresistas existentes mayoritariamente en América Latina hasta hace unos años nos inserta en una relectura más pesimista que vuelve a traer a la luz la tensión constitutiva que los recorre: los diferentes casos nacionales de gobiernos progresistas nos advierten respecto a las conflicti- 
vas relaciones entre modelos de democracia, a los enfrentamientos cada vez más ásperos entre gobiernos progresistas y movimientos sociales, y a las crecientes limitaciones de los proyectos económicos en el marco del neoextractivismo reinante (Svampa, 2015).

A pesar de ello, el soporte de las economías sudamericanas durante los gobiernos progresistas fue, en gran parte, su mercado interno, respaldado por las políticas económicas implementadas. La política económica permitió generar fondos para impulsar inversiones y créditos con fines redistributivos, anticíclicos y de sustitución de importaciones, y consolidar el proceso de industrialización con inclusión y creación de empleo.

No obstante, para Svampa (2015), el neodesarrollismo no es otra cosa que un eufemismo del extractivismo actual, el cual no conduce a un modelo de desarrollo industrial o a un salto de la matriz productiva, sino a más reprimarización (petróleo, minerales, soja, etc.) y a la consolidación de modelos de maldesarrollo, insustentables en diferentes niveles y dimensiones. Como señala Martínez Alier (2015), la bajada de precios de los productos primarios no solo conlleva más endeudamiento, sino también más extractivismo a fin de cubrir el déficit comercial, y con ello los gobiernos suelen entrar en una espiral perversa. No es casual por ello que se realicen anuncios de nuevas exploraciones en zonas de frontera o en parques naturales. Asimismo, el "efecto de reprimarización" se agrava por el ingreso de China, potencia que de modo acelerado se está imponiendo como socio desigual en toda la región latinoamericana. China se ha convertido en el primer destino para las exportaciones de Chile y Brasil, el segundo destino para Argentina, Perú, Colombia y Cuba, y el tercero para México, Uruguay y Venezuela (Svampa y Slipak, 2015).

Por otro lado, el neoextractivismo abrió otra fase de criminalización y violación de derechos humanos. En los últimos años, numerosos conflictos socioambientales y territoriales han salido del encapsulamiento local y han adquirido visibilidad nacional: ejemplos de ello han sido el conflicto del Tipnis (Bolivia), la construcción de la megapresa de Belo Monte (Brasil), la pueblada de Famatina y las resistencias contra la megaminería (Argentina), y la suspensión final de la propuesta de moratoria del Yasuní (Ecuador). Asimismo, estos conflictos socioambientales y territoriales se han acentuado en la actualidad en países con gobiernos de la derecha neoliberal (Colombia, Perú, etc.). Resulta claro que la expansión de la frontera de derechos (colectivos, territoriales, ambientales) encontró un límite en la expansión creciente de las fronteras de explotación del capital en busca de bienes, tierras y territorios, y, desde la perspectiva de estos autores, echó por tierra las narrativas emancipadoras que habían levantado fuertes expectativas, sobre 
todo en países como la Bolivia de Evo Morales y el Ecuador de Rafael Correa. Para Svampa (2015), el fin del boom de los commodities nos sitúa ante la consolidación de la ecuación "más extractivismo/menos democracia" que ilustran los contextos de criminalización de las luchas socioambientales y la desvirtuación de los dispositivos institucionales disponibles (audiencias públicas, consulta previa de poblaciones originarias, consulta pública), escenario que hoy comparten los gobiernos progresistas y los conservadores o neoliberales.

Según Svampa (2015), durante los gobiernos progresistas de Bolivia y Ecuador asistimos a la estigmatización creciente de la narrativa indigenista y ecologista, desplazada por una de corte político donde convergen la visión estatalista y el culto al líder, conforme a esquemas hiperpresidencialistas. Para esta autora, el retorno de un populismo de alta intensidad viene asociado a una política confrontativa que engloba en su interpretación conspirativa a las organizaciones ambientalistas y los sectores indígenas que hoy luchan contra el avance del extractivismo.

En el caso particular de Argentina, Féliz (2012) señala que la diferencia entre la etapa kirchnerista (2003-2015) y la anterior etapa neoliberal es el acuerdo entre los sectores rentistas (sojeros y mineros) con los no rentistas (industriales, comerciales y financieros) respecto de un modelo que privilegia las ventajas comparativas profundizando la inserción extractivista de la economía y desarrollando ramas industriales vinculadas a este complejo exportador. Además, Féliz (2007) sostiene que el neodesarrollismo durante el kirchnerismo presentaba grandes limitaciones. El intento de conformación de una clase industrial transnacionalizada y no rentista con capacidad de absorber las demandas populares en un marco capitalista periférico enfrenta la barrera distributiva (que se manifiesta como inflación, estancamiento salarial y tendencia a la crisis fiscal) con el límite de una economía de baja productividad y heterogeneidad estructural. El neodesarrollismo ha afrontado esas restricciones con un Estado posneoliberal, sin los instrumentos del Estado desarrollista clásico - empresas públicas en sectores estratégicos e instituciones para la intervención en diversas esferas de la reproducción del capital - ni la orientación política que supondría apuntalar una fuerza social de base popular, con posibilidades de desplazar la correlación de fuerzas en una perspectiva de cambio social. Además, se ha ido abriendo un renovado debate sobre los costos sociales y ambientales de este "progreso" (Svampa y Sola Álvarez, 2010), tal como analizamos anteriormente.

Con distinta fortuna, los proyectos neodesarrollistas de la región han buscado superar la histórica contradicción existente entre la industrialización periférica y una persistente inserción primarizada en la economía mundial. Desde los organismos internacionales (como la CEPAL) se plantea que estos países afrontaron 
la necesidad de superar el histórico paradigma desarrollista del "desarrollo hacia adentro", ahora reemplazado por un nuevo esquema conceptual: "el desarrollo desde dentro" (Sunkel, 1991, 1999, 2006). De esa manera, el nuevo desarrollismo pretendió recuperar un programa articulado en torno al desarrollo industrial, pensado como núcleo de un proyecto nacional de desarrollo.

Por ejemplo, Sanmartino (2010) señala como elemento distintivo el papel más activo del Estado argentino durante los primeros doce años de kirchnerismo en la participación y redistribución de las rentas de los sectores extractivos (hacia subsidios industriales y políticas sociales). Este papel activo del Estado se debería justamente a las necesidades de intervención para arbitrar entre fracciones de la gran burguesía, y entre esta y los sectores populares (Basualdo, 2011).

En este proceso de profundización del modelo de desarrollo kirchnerista en Argentina confluyeron dos fuerzas importantes. Una primera fuerza fue la "economía política del modelo primario exportador" (Cantamutto, 2012), donde los sectores primarios (tanto el agro concentrado como la minería) no fueron los sectores "ganadores" (en el sentido de que no fueron los que definieron las políticas) de esta etapa, pero tampoco fueron los sectores desplazados (como sí lo fueron las empresas privatizadas, la banca extranjera y una parte de la gran burguesía agraria). Es decir, a pesar de no ser los "ganadores", pues una parte de la burguesía agraria está dentro de los desplazados del modelo, los sectores primarios siguieron imponiendo un modelo de desarrollo favorable a ellos (Costantino, 2012).

Este modelo de desarrollo primario y concentrado se inserta en una globalización del sistema mundial de alimentos que provoca tal nivel de sobreexplotación de la naturaleza que actúa sobre los bienes comunes como si fueran meros recursos productivos. A nivel comercial, el país se convierte en un "monoproductor" atado a los vaivenes del precio internacional de un commodity como la soja (Teubal, 2006; Giarracca y Teubal, 2010). A nivel tecnológico, se depende exclusivamente del desarrollo de la tecnología que generan las multinacionales, lo cual implica a su vez una apropiación por parte de las mismas de una renta tecnológica (Böcker y Manzoni, 2015).

Varios autores han señalado que este modelo de desarrollo primario exportador fue durante el gobierno kirchnerista la base del financiamiento de los subsidios a la actividad económica (para compensar a los sectores del capital desfavorecidos por la reestructuración de los precios relativos) y de las políticas sociales (necesarias para contener las demandas populares en un contexto de recuperación estructural limitada de sus condiciones de vida). El Estado, como árbitro en un contexto de elevada conflictividad social, requiere de recursos para poder intervenir. De este modo, la influencia de los sectores dominantes y las necesidades 
derivadas del rol del Estado confluyeron en la profundización del modelo primario exportador característico de la etapa kirchnerista en Argentina. Esta profundización precisó la atracción de inversiones extranjeras en proyectos primarioexportadores (monocultivos de soja, grandes proyectos mineros, etc.) debido a la elevada necesidad de recursos que estos proyectos requieren y a las carencias en materia de capacidad técnica y tecnológica de muchos actores nacionales. Así, el neodesarrollismo, según diversos autores, confirmó varias de las tendencias estructurales más perversas del neoliberalismo (extranjerización, concentración de la producción, primarización, relegación estructural de los trabajadores), aunque modificando su modalidad política al requerir mayores intervenciones del Estado y canalizar la movilización popular.

Ahora bien, los últimos años del gobierno kirchnerista deberían ser evaluados por su capacidad para afrontar una coyuntura difícil sin haber alterado los objetivos principales de desarrollo industrial, generación de empleo e inclusión social. En lugar de recurrir al ajuste del gasto público y al achicamiento del déficit fiscal (tal y como promovió posteriormente el gobierno neoliberal de Macri), el Estado intentó promover la inversión y el consumo internos, actuando de este modo de manera contracíclica a las tendencias de recesión económica (Böcker y Manzoni, 2015). Sin embargo, es importante preguntarse por qué el kirchnerismo, al igual que otros gobiernos progresistas sudamericanos, siguió basándose durante doce años en el modelo extractivista de exportación de commodities, y por qué no ha podido o no ha tenido la voluntad política para hacer reformas estructurales en el modelo agrario.

\section{Conclusiones}

Con la llegada al poder de López Obrador en México, de Alberto Fernández y Cristina Kirchner en Argentina y de Luis Arce en Bolivia, el actual escenario político latinoamericano está caracterizado por una nueva correlación de fuerzas entre grupos de países de diferente signo político-ideológico. Sin duda alguna, ello representa un freno a la derechización en la región en los últimos años.

En América Latina, al igual que en gran parte del mundo, se enfrentan dos modelos socioeconómicos y políticos antagónicos. No es verdad que ya no existan la izquierda y la derecha. Solo han cambiado sus formas y, también, sus estereotipos. Y ello se ha podido observar también en un contexto tan particular como ha sido el de la pandemia del coronavirus a escala mundial durante el año 2020: representantes del llamado populismo de derecha, como Donald Trump, Boris Johnson y Jair Bolsonaro, han subestimado sus efectos, limitando así las medidas vinculadas al confinamiento, al distanciamiento social y al uso de tapabocas. 
La relación entre libertad e igualdad, tal vez el tema central de la teoría política a partir de Rousseau, ocupó un lugar central en la obra de Norberto Bobbio. Para Bobbio (1995), el criterio más frecuentemente adoptado para distinguir la derecha de la izquierda es la diferente actitud que asumen los hombres que viven en sociedad en relación con el ideal de la igualdad: la derecha tiende a privilegiar la libertad, mientras que la izquierda, la igualdad. Bobbio no está pensando solo en la igualdad ante la ley y en cuanto a la participación política de los ciudadanos mediante el sufragio universal. Tampoco está pensando en la llamada igualdad de oportunidades. En lo que está pensando Bobbio (1995) es en la igualdad material, en la igualdad en las condiciones de vida de la gente. Desde su punto de vista, lo que interesa preferentemente a la izquierda, y no a la derecha, es avanzar más rápido hacia dicha igualdad material, a fin de conseguir sociedades y modos de vida donde la libertad de las personas vaya acompañada de unas condiciones materiales de vida — educación, salud, trabajo, vivienda — que hagan realmente posible y atractivo el ejercicio de una libertad que sin esas condiciones se transforma en algo casi enteramente ilusorio y vacío para quienes viven en grosera situación de desigualdad respecto a sus semejantes (Squella, 1995).

Podemos llamar a eso igualdad, equidad o justicia social, "pero de lo que se trata, según el ideario de la izquierda, es de utilizar los instrumentos de la política, y no solo los más lentos de la economía, a fin de que todos disfruten de unas condiciones materiales de vida que guarden relación con la dignidad que se proclama de la especie humana en general y de cada individuo en particular. Para conseguir esa finalidad, la izquierda tiene entonces que activar una mayor preocupación por hacer realidad los derechos económicos y sociales, una clase de derechos humanos basada precisamente en los valores de la igualdad y la solidaridad, y no contentarse con el solo reinado de esa otra categoría de derechos fundamentales - la de los derechos personales-, basados por su parte en el valor de la libertad" (Squella, 1995: 425). Por ello, si no hay igualdad no hay libertad.

En América Latina, los derechos sociales y económicos se han ido concretando históricamente mediante nueva legislación inclusiva, regulación de mercados y de sectores económicos, controles en las cadenas de valor, nacionalización de empresas estratégicas, reforma agraria, reformas fiscales más progresivas, etc. Sin embargo, si bien este tipo de políticas públicas está asociado en general a gobiernos de izquierda de todo tipo, también durante ciertos períodos y países ha habido casos en donde gobiernos centristas, e incluso de derecha nacionalista, aplicaron políticas estatistas, a nivel social, económico, fiscal y de obra pública, a partir de la década de 1930, especialmente durante las tres décadas posteriores a la Segunda Guerra Mundial. De igual manera, pero de manera inversa, la iz- 
quierda a veces ha ido en contra de su ideario igualitario. Por ejemplo, a partir de la década de 1990 muchos gobiernos latinoamericanos con un ideario histórico de centroizquierda han aplicado políticas de ajuste neoliberal. Todo ello debe obligarnos a pensar Latinoamérica con una mirada crítica y renovada.

\section{Bibliografía}

BASUAldo, E. (2011). Sistema politico y modelo de acumulación: tres ensayos sobre la Argentina actual. Buenos Aires: Atuel.

Воввіо, N. (1995). Derecha e izquierda. Razones y significados de una distinción política. Madrid: Taurus.

Böcker, R. (2014). “Ortodoxia y políticas de austeridad en Europa”. Revista de Ciencias Sociales, 144 (2), 133-145.

Böcker, R.y Manzoni, M. (2015). “Planificación en la política agropecuaria de Argentina”. Revista Internacional de Organizaciones, 15, 7-27.

Bresser-Pereira, L. (2007). "Estado y mercado en el nuevo desarrollismo". Nueva Sociedad, 210, 110-125.

Brunet, I. y Böcker, R. (2007). Desarrollo, industria y empresa. Madrid: Tecnos.

Brunet, I. y Böcker, R. (2013). Capitalismo global: aspectos sociológicos. Madrid: Grupo 5.

Brunet, I. y Böcker, R. (2015). "Desarrollo sostenible, humano y endógeno”. Revista Estudios Sociológicos, 98 (33), 311-335.

Bustelo, P. (1998). Teorías contemporáneas del desarrollo económico. Madrid: Síntesis.

Cantamutto, F. (2012). Economía política de la política económica: Coaliciones de gobierno y Patrón de acumulación en Argentina, 1998-2008. México: FLACSO.

Casparrino, C. (2008). "Nuevos dilemas del desarrollo periféricoः notas sobre la heterodoxia conservadora, democracia y cambio social". Revista del CCC [online] 4 (septiembre-diciembre).

Costantino, A. (2012). La pampa sigue ancha y ajena. La persistencia del poder terrateniente en la región pampeana argentina en la etapa de la sojización. México: FLACSO.

Dockendorff, A. y Kaiser V+ (2009). "Populismo en América Latina. Una revisión de la literatura y la agenda”. Revista Austral de Ciencias Sociales, 17, 75-100.

Dornbusch, R. y Edwards, S. (1991). "The Macroeconomics of Populism". En R. Dornbusch y S. Edwards (eds.), The macroeconomics of Populism in Latin America (pp.7-13). Chicago: University of Chicago Press. 
Edwards, S. (2008). "La larga historia de América Latina con un bajo crecimiento económico”. En P. Sснміdт у Á. Sото (eds.), Las frágiles democracias latinoamericanas. Santiago: El Mercurio Aguilar.

FÉliz, M. (2007). "¿Hacia el neodesarrollismo en Argentina? De la reestructuración capitalista a su estabilización". Anuario EDI: Economía Argentina ¿Coyuntura favorable o nuevo modelo? Buenos Aires: Ediciones Luxemburg, Economistas de izquierda, 68-81.

FÉliz, M. (2008). "Los límites macroeconómicos del neodesarrollismo". Herramienta. Revista de debate y crítica marxista, 39, 97-116.

FÉliz, M. (2012)."Neoextractivismo, neodesarrollismo y proceso de acumulación de capital. ¿Superando el ciclo stop-and-go?”. Argentina, 2003-2012. VII Jornadas de Sociología de la UNLP. Argentina en el escenario latinoamericano actual: debates desde las ciencias sociales. La Plata: FAHCE UNLP.

Fitoussi, J.-P. y Rosanvallon, P. (1996). Le nouvel âge des inégalités. París: Editions du Seuil.

Gereffi, G. (2001), "Las cadenas productivas como marco analítico para la globalización". Problemas del desarrollo, 32 (125), 9-37.

Giarracca, N. y Teubal, M. (2010). “Disputas por los territorios y recursos naturales: el modelo extractivo". Revista ALASRU Nueva Época, 5 (1), 113-133.

Laclau, E. (2005). La Razón populista. México D.F.: Fondo de Cultura Económica.

Laclau, E. y Mouffe, Ch. (1987). Hegemonía y estrategia socialista. Hacia una radicalización de la democracia. Madrid: Siglo XXI.

Mackinnon, M. y Petrone, M. (1998). "Los complejos de la Cenicienta”. En M. Mackinnon y M. Petrone (comps.), Populismo y neopopulismo en América Latina; el problema de la Cenicienta (pp. 13-56). Buenos Aires: Editorial Universitaria.

Martínez Alier, J. (2015). "Sudamérica, el triunfo del post-extractivismo en el 2015". La Jornada [online], <http://www.jornada.unam.mx/2015/02/21/ opinion/022a1mun>.

Mouffe, Ch. (2018). Por un populismo de izquierda. Buenos Aires: Siglo XX Editores.

Nahon, C.; Rodríguez, C. y Schorr, M. (2006). "El pensamiento latinoamericano en el campo del desarrollo del subdesarrollo: trayectoria, rupturas y continuidades". Crítica y teoría en el pensamiento social latinoamericano, Buenos Aires, CLACSO: 327-388.

Oliver, L. (2016). "América Latina y Brasil: vuelco a la derecha y crisis política”. Revista Memoria, 260 (4), 38-44. 
Paramio, L. (2006). "Giro a la izquierda y regreso del populismo”. Nueva Sociedad, 205, 62-74.

Pinazo, G. y Piqué, P. (2011). "Desarrollo latinoamericano en el marco de la globalización”. Revista Problemas del Desarrollo, 166 (42), 7-35.

Poblete, M. (2006). "Populismo latinoamericano: Una perspectiva comparada". Revista de Ciencias Sociales, 3 (3), 71-95.

Romo, G. (2007). "La teoría del desarrollo: reflexiones para una estrategia alternativa frente al neoliberalismo". En Repensar la Teoría del desarrollo en un contexto de globalización. Homenaje a Celso Furtado, Buenos Aires, CLACSOUAMI.

Ruiz, J. (2006). "Reseña a La razón populista de Ernesto Laclau". Revista Confines, 2, 103-107.

Sachs, J. D. (1990). Social Conflict and Populism Politics in Latin America. San Francisco: ICS Press.

Sanmartino, J. (2010). "Crisis, acumulación y forma de estado en la Argentina post-neoliberal". Cuestiones de Sociología-Revista de Estudios Sociales, 5, 235-253.

Squella, A. (1995). "Derecha e izquierda: la igualdad hace la diferencia”. Estudios Públicos, 60, 415-429.

Sunkel, O. (1991). El desarrollo desde dentro. Un enfoque neoestructuralista para la América Latina. México: Fondo de Cultura Económica.

Sunkel, O. (1999). El subdesarrollo latinoamericano y la teoría del subdesarrollo. México: Siglo XXI.

Sunkel, O. (2006). "En busca del desarrollo perdido". Revista Problemas del Desarrollo, 147 (37), 13-44.

Svampa, M. (2015). "América Latina: de nuevas izquierdas a populismos de alta intensidad”. Revista Contrapunto, 7, 83-96.

Svampa, M. y Slipak, A. (2015). "China en América Latinaः del Consenso de los Commodities al Consenso de Beijing". Revista Ensambles, 3, 34-63.

Svampa, M. y Sola Álvarez, M. (2010). "Modelo minero, resistencias sociales y estilos de desarrollo: los marcos de la discusión en la Argentina". Ecuador Debate, 79, 105-126.

Teubal, M. (2006). "Expansión del modelo sojero en la Argentina. De la producción de alimentos a los commodities". Realidad Económica, 220 (mayojunio), 71-96.

Williamson, J. (1990). Latin American Adjustment. Washington D.C.* Institute of International Economics. 